\title{
Prosthodontic Management of a 10-day-old Neonate with Cleft Palate Using a Feeding Appliance: A Case Report
}

\author{
Sanju Malik ${ }^{1}$, Manu Rathee ${ }^{2}$, Aditi Singh ${ }^{3}$, Smriti Kaushik $^{4}$, I Vinith $^{5}$
}

\section{Abstract}

Cleft lip and palate have a complex mode of inheritance and affects several systems and their functions such as facial growth, eruption of teeth, feeding of the newborn, speech, and hearing. It can be associated with many syndromes. Fabrication of a feeding appliance helps with the proper nourishment which has a positive impact on the growth and development of the infant. Clinician should have proper knowledge and understanding of the dental materials and specific impression techniques used in the fabrication of feeding plate.

Keywords: Cleft palate, Feeding plate, Neonate.

Journal of Oral Health and Community Dentistry (2019): 10.5005/jp-journals-10062-0058
\end{abstract}

\section{INTRODUCTION}

Cleft lip and palate are one of the most common congenital deformities of orofacial region and it is associated with high rate of morbidity. Both environmental and genetic factors are responsible for orofacial clefts and it occurs in 1 in 700 live births. ${ }^{1}$ Environmental factors such as viral infections, vitamin and mineral deficiencies, radiation exposure, and excessive use of drugs like insulin, certain antibiotics, and steroids particularly affects in the first trimester. Genetically these defects are sex-linked recessive affecting the males. ${ }^{2}$

It has debilitating effect on feeding, dentition, mastication, facial growth, deglutition, esthetics, breathing, and speech. ${ }^{2}$ Management of cleft palate is a team approach including a number of healthcare personnel involvement like pediatrician, otolaryngologist, orthodontist, prosthodontist, speech therapist, and many others. ${ }^{3}$ Treatment aims to help patient lead a normal and competent life and it is greatly regulated by the age of the patient. Feeding an infant with cleft lip and palate particularly becomes difficult for the parents. In that case, a feeding appliance obturates the cleft and helps in formation of positive seal which helps in feeding. With the advancing age, treatment is generally a supportive one.

The present case report elaborates the prosthodontic management of cleft palate in 10-day-old healthy neonate with a feeding appliance.
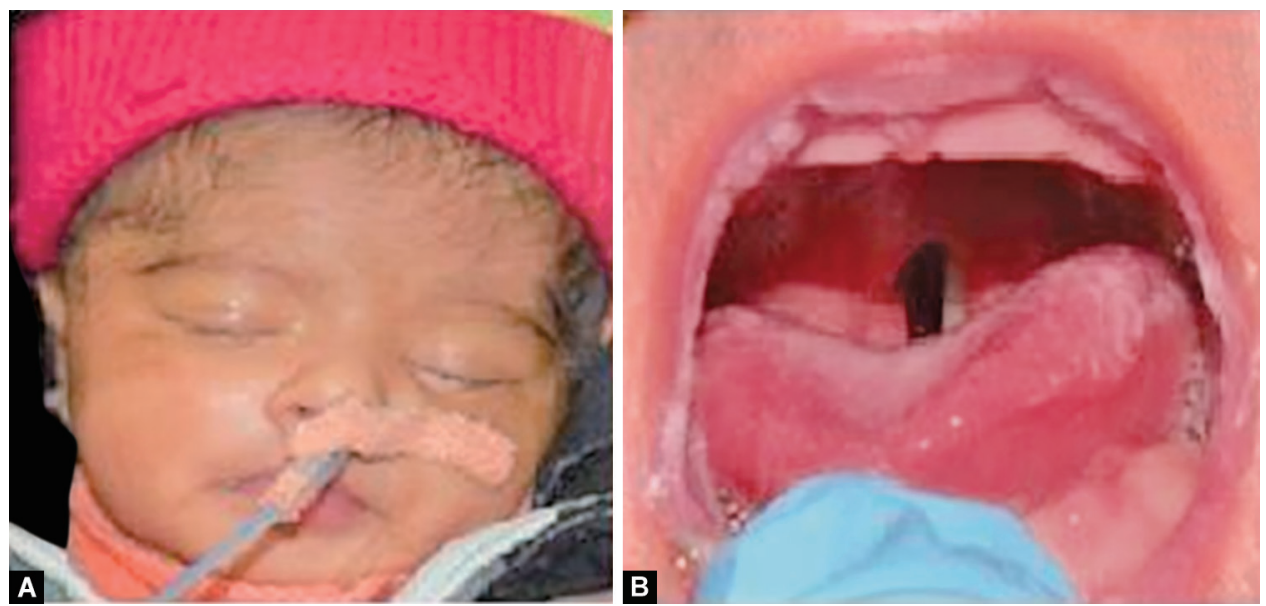

Figs 1 A and B: (A) Ex view; (B) Intraoral view showing cleft palate
1,4,5 Department of Prosthodontics, Postgraduate Institute of Dental Sciences, Rohtak, Haryana, India

${ }^{2}$ Department of Prosthodontics and Crown and Bridge, Postgraduate Institute of Dental Sciences, Rohtak, Haryana, India

${ }^{3}$ Department of Prosthodontics, Postgraduate Institute of Dental Sciences, New Delhi, India

Corresponding Author: Sanju Malik, Department of Prosthodontics, Postgraduate Institute of Dental Sciences, Rohtak, Haryana, India, Phone: +91 9911082248, e-mail: smsanju2011@gmail.com

How to cite this article: Malik S, Rathee M, Singh A, et al. Prosthodontic Management of a 10-day-old Neonate with Cleft Palate Using a Feeding Appliance: A Case Report. J Oral Health Comm Dent 2019;13(3):112-114. Source of support: Nil

Conflict of interest: None

\section{Case Description}

A healthy 10-day-old male neonate reported to the Department of Prosthodontics with the parents complaining of regurgitation of fluids through nose (Fig. 1A). Mother was unable to bottle- and breastfeed the neonate. On examination, neonate was found

(c) The Author(s).2019 Open Access This article is distributed under the terms of the Creative Commons Attribution 4.0 International License (https://creativecommons. org/licenses/by-nc/4.0/), which permits unrestricted use, distribution, and non-commercial reproduction in any medium, provided you give appropriate credit to the original author(s) and the source, provide a link to the Creative Commons license, and indicate if changes were made. The Creative Commons Public Domain Dedication waiver (http://creativecommons.org/publicdomain/zero/1.0/) applies to the data made available in this article, unless otherwise stated. 

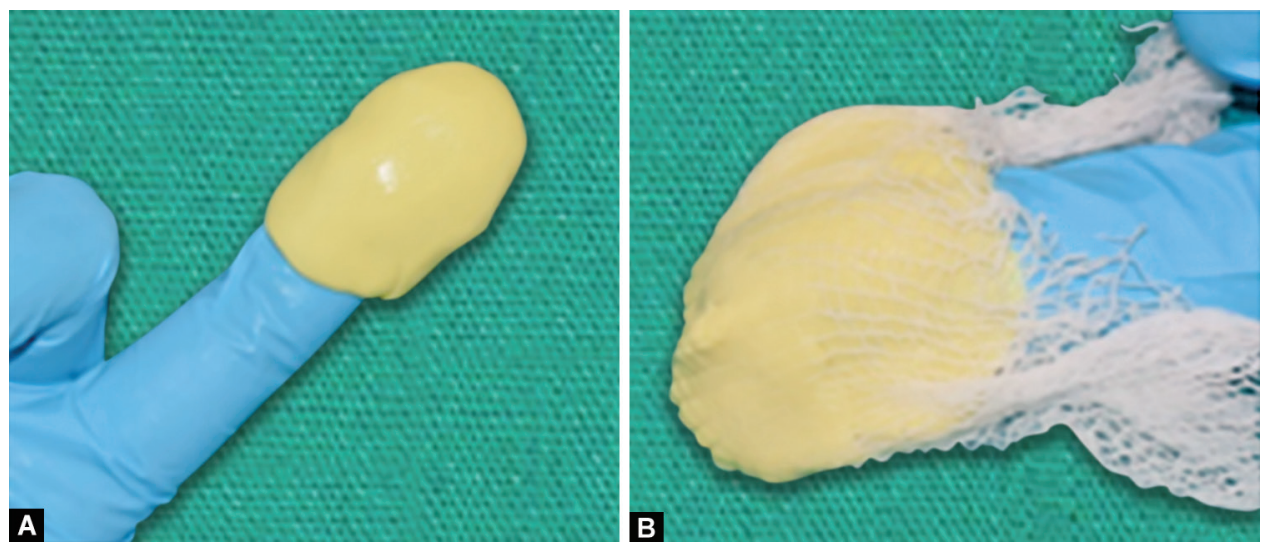

Figs 2A and B: (A) Index finger coated with putty; (B) Putty impression with safety gauge
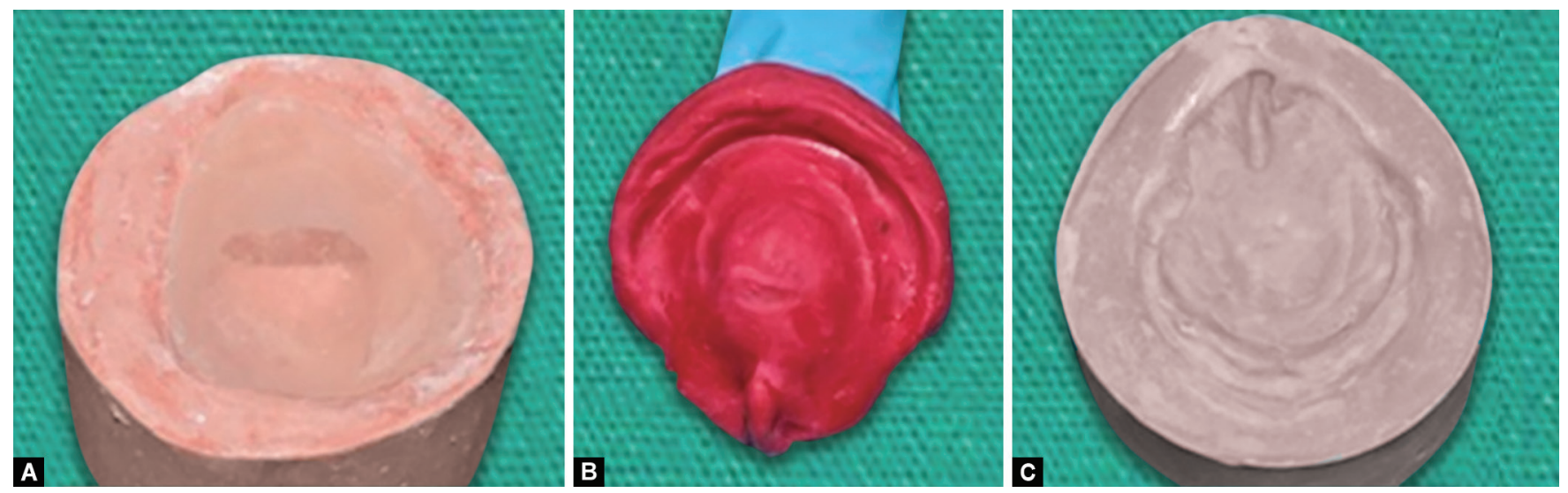

Figs 3 A to C: (A) Special tray; (B) Impression compound final impression; (C) Working cast

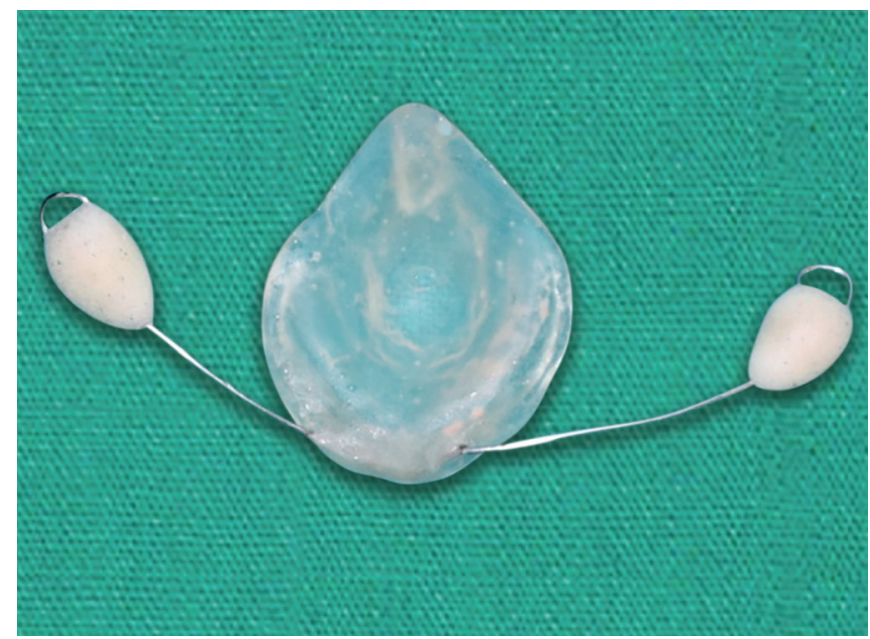

Fig. 4: Feeding plate

to have Veau's $4^{4}$ isolated cleft palate and nasogastric tube was placed in the left nostril (Fig. 1B). After consulting the parents, it was decided to fabricate a feeding appliance for the patient.

One of the parents was seated in dental chair holding the neonate in his lap facing the head in the forward direction. The elastomeric impression was made using the operator's index finger as oral cavity was too small for any type of impression trays (Fig. 2A). The patient was made to suckle on the elastomeric material coated finger to record the soft palate defect appropriately (Fig. 2B).

The impression was poured and a special tray was fabricated to make the final impression (Fig. 3A). Special tray was checked in patient's mouth and adjusted accordingly. Final impression was made by manipulating impression compound by making the patient to do the suckling movements to record the edentulous ridges and the palatal defect (Fig. 3B). Final impression was poured after doing appropriate beading and boxing (Fig. 3C). The cast was retrieved and unfavorable undercuts were blocked.

Feeding appliance was fabricated using self-cure acrylic resin and 22 gauge wires were placed to support the appliance extraoral (Fig. 4). Appliance was checked in the neonate's mouth regarding coverage of the defect as well as the extension of the borders. The mother was explained about the method of insertion and feeding technique to be used with the feeding appliance (Fig. 5).

After the delivery of the appliance, mother was successfully able to feed the infant. Postinsertion instructions were given regarding the cleaning and maintenance of the appliance. Mother was advised to hold the patient in upright or semi upright position while feeding. The feeding plate insertion was done on the same appointment. Regular follow-up is required after the appliance insertion as the oral mucosa is very delicate and prone to injuries. 

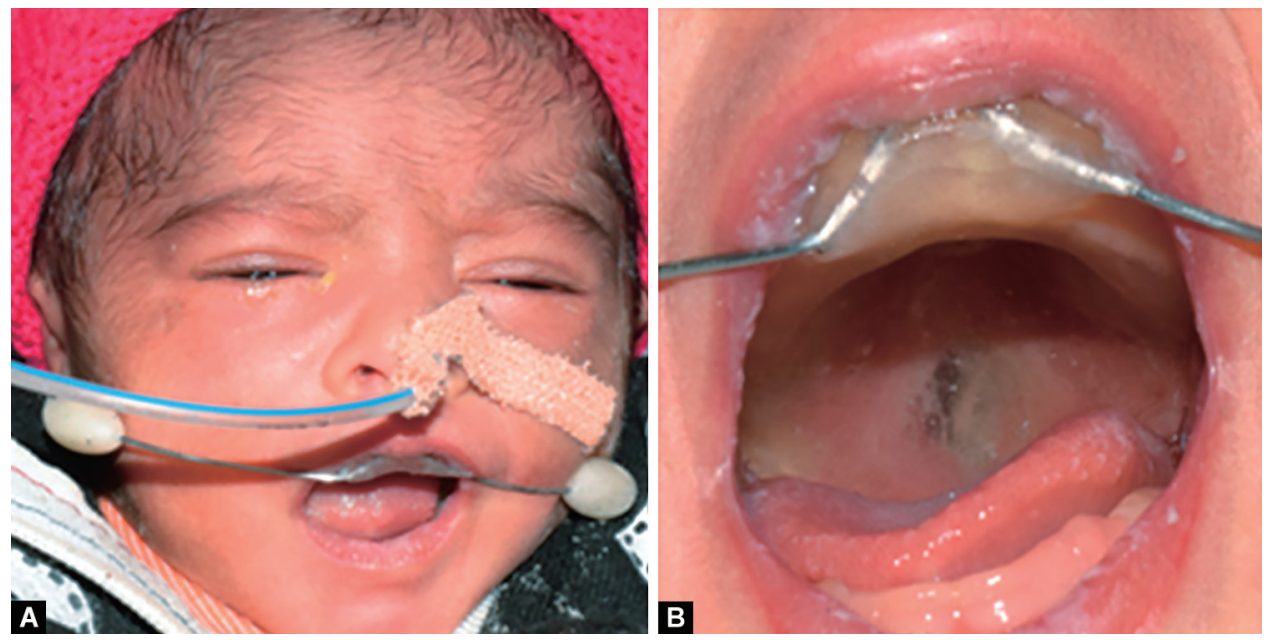

Figs 5A and B: (A) Feeding plate intraoral view; (B) Feeding plate extraoral view

\section{Discussion}

The treatment for cleft palate varies according to the presentation and extent of the defect and the age of the patient. The primary objective of treatment of an infant suffering from cleft palate is proper feeding so that it does not hamper proper growth of the child. A feeding appliance is very important for the adequate nourishment of the growing neonate. ${ }^{5}$

Treating a newborn poses many challenges to a clinician. The first and foremost difficulty is recording the defect properly. The oral cavity of a neonate is too small for use of any commercially available trays to make an impression. ${ }^{6}$ Also, there is always a risk of swallowing and aspiration of impression material. Care should be taken while choosing the impression material for its setting time, consistency, and flow rate. Patient's head position is another important factor to be considered while making an impression to maintain the airway patency. ${ }^{6}$

Relieving the unfavorable undercuts of the defect and oral cavity minimizes the impression tear and helps in its easy retrievability. Neonate crying is satisfactory for ensuring airway patency and reduces the risk of impression material aspiration. ${ }^{7}$ Heavy putty-type elastomeric impression material was used to make impression in the current case because of its high viscosity and ability to record the proper details. ${ }^{8}$

The feeding plate was made with self-cure acrylic resin so that the appliance can be delivered on the same day of the appointment. It helps with the feeding of the neonate and reduced the mother's anxiety. ${ }^{9,10}$

\section{Conclusion}

Sufficient knowledge of different cleft and growth patterns is important to choose an impression technique and fabrication of appliance. Feeding appliance should be fabricated as soon as possible after birth for the better feeding of the newborn.
It promotes the health of the patient as well as has a positive psychological influence on the parents. Feeding appliance should be changed every 2-3 months to match the growing maxilla, palatine shelves, and soft tissue.

\section{References}

1. Madeleine LB, Chai Y, Yao CA, et al. Epidemiology, etiology, and treatment of isolated cleft palate. Front Physiol 2016;7:67. DOI: 10.3389/fphys.2016.00067.

2. Rathee M, Hooda A, Tamarkar A, et al. Role of feeding plate in cleft palate: case report and review of literature. Int J Otorhinolaryngol 2009;12(1):1-6.

3. Tervo RC, Chudley AE. Management of cleft lip and palate: a team approach. Can Fam Physician 1981;27:1964-1970.

4. Khan $\mathrm{M}$, Ullah $\mathrm{H}, \mathrm{Naz} \mathrm{S}$, et al. A revised classification of the cleft lip and palate. Can J Plast Surg 2013;21(1):48-50. DOI: $10.1177 / 229255031302100102$.

5. Rathee M. Single visit feeding appliance for 1-day-old neonate with cleft palate using safe dental putty-gauze hybrid impression technique for maxillary impression. J Surg Tech Case Rep 2015;7(1): 7-11. DOI: 10.4103/2006-8808.184938.

6. Shajahan PA, Raghavan R, Bos R, et al. Prosthodontics approach for the fabrication of feeding plates in cleft palate patients. Sci J Clin Med 2016;5:31-36.

7. Moness Ali AM, Abdullah K. A single visit feeding plate for a 3 month old infant with cleft palate. A case report. J Dent Res Dent Clin Dent Prospects 2017;11(4):253-256. DOI: 10.15171/joddd.2017.044.

8. Gupta R, Singhal P, Mahajan K, et al. Fabricating feeding plate is CLP infants with two different material: a series of case report. J Indian Soc Pedod Prev Dent 2012;30(4):352-355. DOI: 10.4103/0970-4388.108943.

9. Tamrakar AK, Yunus N, Rathee M, et al. Prosthodontic management of a case with surgically treated cleft lip and palate with residual oro-nasal fistula. Ann Dent Specialty 2013;1(1):29-30.

10. Agarwal A, Rana V, Shafi S. A feeding appliance for a newborn baby with cleft lip and palate. Natl J Maxillofac Surg 2010;1(1):91-93. DOI: 10.4103/0975-5950.69149. 